International Journal of Applied Pharmaceutical Sciences and Research 2016; 1(3): 96-103
International Journal of Applied

Original Research

\title{
Neuroprotective effect of pterostilbene on ketamine induced schizophrenia in mice
}

\author{
Devender Palsa ${ }^{1}$, Nazia Begum ${ }^{2}$, Jeevan Kommidi ${ }^{1}$, Kapishwar Singh $^{1}$, Mahipal Yellu ${ }^{1}$, Dr Vasudha Bakshi ${ }^{3}$.
}

1. Dept. of Pharmacology, Lalitha College of Pharmacy, Anurag Group of Institutions, Ghatkesar, Hyderabad, Telangana, India.

2. Faculty, Dept. of Pharmacology, Lalitha College of Pharmacy, Anurag Group of Institutions, Ghatkesar, Hyderabad, Telangana, India.

3. Principal, School of Pharmacy, Anurag Group of Institutions, Ghatkesar, Hyderabad, Telangana, India.

Corresponding author: Vasudha Bakshi

Address: Dept. of Pharmacology, Lalitha College of Pharmacy, Anurag Group of Institutions, Ghatkesar, Hyderabad, Telangana, India.

Article History:

Received: 17 May 2016

Accepted: 5 July 2016

Available online:

\section{Keywords:}

Neuroprotective;

Ketamine; Pterostilbene;

Schizophrenia

\section{ABSTRACT:}

Objective: The aim of this study is to investigate the effects of pterostilbene on the behavior of mice and oxidative stress under the influence of Ketamine induced schizophrenia model.

Methods: Schizophrenia was induced in mice by ketamine $(50 \mathrm{mg} / \mathrm{kg} / \mathrm{day}$, i.p, for 14 days). The treatment effect of pterostilbene (10 and $20 \mathrm{mg} / \mathrm{kg} /$ day, p.o, for 14 days) were verified on Actophotometer, Y-maze, Forced swim test (FST), open field apparatus, acetylcholinesterase activity and anti oxidant stress-related biomarker (Catalase, GSH, TBARS, SOD) levels in brain tissues.

Results: Pterostilbene decreased TBARS, AChE and increased SOD, CAT, GSH levels in mice brain when compared with control group. It also improved spatial recognition memory, decreased mobility time, decreased exploratory behaviour and locomotor activity as evident by improved performance in Y-Maze task, Forced swim test, Open field test and Locomotor activity test. Conclusion: Pterostilbene has a neuroprotective role related atleast in part to an antioxidant mechanism and Anti AChE activity, which could be explored as more effective therapies of schizophrenia and other psychiatric diseases.

Neuroprotective, Ketamine, Pterostilbene, Schizophrenia,

\section{Introduction}

Schizophrenia is a chronic debilitating multifactor disorder of mind with a constant prevalence of $1-2 \%$ in the population (Yue Hou et al., 2013; Uma Devi et al., 2014; Nandini et al., 2010) and characterized by profound disturbance of perception, cognition, emotion, and social function (Uma Devi et al., 2014). The glutamate receptor theory indicates the involvement of glutamate receptors in pathophysiology of mood disorders (Mahajan et al., 2013; Uma Devi et al., 2014). Hypofunctional N-methyl-D-aspartate (NMDA) receptor signaling, particularly in the prefrontal cortex, has been implicated in the cognitive and behavioral disturbances seen in schizophrenia. Exposure to non-competitive NMDA receptor antagonists, such as phencyclidine (PCP) and ketamine, induces a broad range of antipsychotic sensitive and schizophrenia-like behavioral abnormalities in healthy individuals and exacerbates the same symptoms in schizophrenic patients. These
Schizophrenia-like behaviors have been attributed to the blockade of synaptic NMDA receptors by these drugs (Chan et al., 2012).

Drugs prescribed for the treatment of psychosis can be categorized as typical and atypical. The typical classes of antipsychotics are effective against the positive symptoms, i.e. hallucinations, delusions, etc. and also possess extra-pyramidal side effects. Whereas the atypical class are effective in ameliorating the positive, negative as well as the cognitive symptoms and possess lesser extra-pyramidal side effects but in turn hold greater risk of cardiovascular diseases, diabetes and agranuloctosis etc. Regular intake of these agents may also increase oxidative load and thereby further enhance the progression of the disease. In a scenario like this we need drugs with lesser side effects (Chatterjee et al., 2011). Pterostilbene is a phenolic compound chemically similar to resveratrol (Remsberg et al., 2008). Initially 
isolated from sandalwood and other natural sources of pterostilbene are various herbal drugs, for example, leaves and grapes of Vitis vinifera, Vaccinium spp., and Pterocarpusmarsupium (Grover et al., 2005; Langcake et al., 1979; Paul et al., 1999). It is also found in fruits including grapes and blueberries, known for their beneficial effects on learning and memory impairment possibly via inhibiting microglia activation and protecting neuronal injury in mice (Hou et al., 2014) and neuronal function during aging. It is a potent antioxidant and anti-inflammatory agent shown to have beneficial effects in methamphetamine-induced hyperactivity, (Miller et al.,2013) hyperglycimea, (Satheesh and Pari, 2008; Manickam et al., 1997) the aging brain and in Alzheimer's disease (Joseph et al., 2008; Remsberg et al., 2008; Rimando et al., 2002; Chang et al., 2012).Interestingly, in vitro, it has higher potency at inducing apoptosis in cancer cells than resveratrol (Mikstacka et al., 2007), and shows powerful agonistic properties on the peroxisome proliferator activated receptor (PPAR) alpha receptor (Rimando et al., 2005; Satheesh and Pari, 2008) a receptor complex that is intimately associated with fatty acid metabolism, inflammation, and oxidative stress regulation, and antagonistic properties on GSK3 $\beta$ in GSK3 $\beta / \beta$-catenin pathway (Chen et al., 2014). In this study our hypothesis is that pterostilbene protects from schizophrenia by acting on GSK3 $\beta$ signaling pathway and rescues ketamine induced behavioural changes and oxidative stress.

\section{Materials and methods:}

\subsection{Experimental animals}

Swiss albino mice, weighing 20-35g, at the age 3-4 weeks were used in the study. They were maintained on standard laboratory pellet chow diet; Provimi limited (India), provided water ad libitum and were kept under standard conditions at $23-250 \mathrm{c}, 35$ to $60 \%$ humidity, and $12 \mathrm{hr}$ light /dark cycle. The mice were acclimatized to the laboratory conditions a week prior to experiment. The experimental protocol was duly approved by institutional animal ethics committee (IAEC) and care of the animals was carried out as per the guidelines of committee for the purpose of control and supervision of experiments on animals (CPCSEA) (Protocol.No: I/IAEC/LCP/003/2014/SM/30).

\subsection{Drugs and chemicals}

Pterostilbene was gift sample from SAMI LABS Bangalore, India. Ketamine was purchased from local hospital, hyderabad. DTNB (5,5'-dithiobis(2nitrobenzoicacid)), Eserine, Acetylthiocholine iodide, Reduced Glutathione were purchased from Sigma Aldrich, USA. 2-Thiobarbituric acid was purchased from Himedia laboratories Pvt Ltd, Mumbai. All other reagents of Analytical grade are from S. D Fine chemicals Ltd, India.

\subsection{Induction of Schizoprenia and} grouping/Experimental protocol

Schizoprenia is induced by chronic administration of Ketamine $(50 \mathrm{mg} / \mathrm{kg} /$ day $)$ for 14 days.

Animals were randomly divided into five groups of each six mice. Group I: vehicle control received $0.5 \%$ CMC(carboxy methyl cellulose) (p.o), Group II: ketamine control received only with Ketamine(i.p), Group III and IV animals were injected with Ketamine and treated with 10 and $20 \mathrm{mg} / \mathrm{kg}$ (p.o) Pterostilbene (PTR). Except vehicle control group all the animals received Ketamine injection for 14 days.

\subsection{Behavioural assessment}

\subsubsection{Locomotor activity}

Spontaneous locomotor activity was measured in actophotometer having dimensions of $39 \times 28 \times 26 \mathrm{~cm}$. The breakage of photobeams was monitored with infrared sensors and automatically recorded for $5 \mathrm{~min}$ (Elder et al., 2008).

\subsubsection{Video tracking in Y Maze}

Y-maze task used to measure the spatial working memory in mice. The maze is made of gray plastic. Each arm is $40 \mathrm{~cm}$ long, $13 \mathrm{~cm}$ high, $3 \mathrm{~cm}$ wide at the bottom, $10 \mathrm{~cm}$ wide at the top, and converged at an equal angle. Each mouse was placed at the end of one arm and allowed to move freely through the maze for 8 mins. Mice tend to explore the maze systematically, entering each arm in turn. The ability to alternate requires that the mice know which arm they have already visited. The series of arm entries, including possible returns into the same arm is recorded. Alteration is defined as the successive entries into the three arms, on overlapping triplet sets. The percentage of alteration is calculated as the ratio of actual alterations to possible alterations, defined as the total number of arm entries minus two, and multiplied by hundred. Typically, mice exhibit an alteration percentage of $60-70 \%$, and perform 25-35 arm entries within the 8 min session (Sharath et al., 2016).

\subsubsection{Open field habituation}

The exploratory behaviour of the mice was evaluated by open field habituation task method. Mice was placed in a $40 \mathrm{~cm} \times 50 \mathrm{~cm} \times 60 \mathrm{~cm}$ open field whose brown linoleum floor was divided into 12 equal squares by white lines and left to explore it freely for 5 minutes. The number of line crossings and head dippings were counted (Maria et al., 2005, Fendt et al., 2008).

\subsubsection{Forced swimming test}

The forced swimming test was performed as previously reported (Noda et al., 1997, Noda et al., 2000). In brief, mice were placed individually in glass cylinders $(20 \mathrm{~cm}$ height, $12 \mathrm{~cm}$ diameter) containing $10 \mathrm{~cm}$ depth of water at $25{ }^{\circ} \mathrm{C}$. After $5 \mathrm{~min}$, the animals were removed from water, dried and returned back to their home cages. They 
were again placed in the cylinder $24 \mathrm{~h}$ later and the total duration of immobility was measured for $3 \mathrm{~min}$. Mice which were floating motionless were considered to be immobile.

\subsection{Biochemical Estimations}

\subsubsection{Estimation of Acetylcholinesterase}

Brain tissue was homogenized in Phosphate buffer ( $\mathrm{pH} 8$, $0.1 \mathrm{M}$ ) in a Potter Elvehjem homogenizer. $0.5 \mathrm{ml}$ of supernatant liquid of the brain homogenate was pipetted out into $25 \mathrm{ml}$ volumetric flask and dilution was made with a freshly prepared DTNB solution (10 mg DTNB in $100 \mathrm{ml}$ of Sorenson phosphate buffer, $\mathrm{pH}$ 8.0). From the volumetric flask, two $4 \mathrm{ml}$ portions were pipette out into two test tubes. Into one of the test tube, 2 drops of eserine solution was added. $1 \mathrm{ml}$ of substrate solution (75 $\mathrm{mg}$ of acetylcholine iodide per $50 \mathrm{ml}$ of distilled water) was pipetted out into both of the test tubes and incubated for $10 \mathrm{~min}$. at $30^{\circ} \mathrm{C}$. The solution containing eserine solution was used for zeroing the colorimeter and change in absorbance per min. of the sample was read spectrophotometrically (UV-1800, Shimadzu) at $420 \mathrm{~nm}$. The enzyme activity is expressed as $\mu$ moles/minute/mg protein (Avinash et al., 2016).

\subsubsection{Estimation of Reduced Glutathione (GSH)}

GSH was determined by its reaction with 5, 5-dithiobis (2-nitrobenzoic acid) (Ellman's reagent) to yield a yellow chromophore which was measured spectrophotometrically. The brain homogenate was mixed with an equal amount of $10 \%$ trichloroacetic acid (TCA) and centrifuged (Remi cold centrifuge) at $2000 \times \mathrm{g}$ for $10 \mathrm{~min}$ at $4{ }^{\circ} \mathrm{C}$. To $0.1 \mathrm{ml}$ of processed tissue sample, $2 \mathrm{ml}$ of phosphate buffer ( $\mathrm{pH} 8.4$ ), $0.5 \mathrm{ml}$ of 5, 5-dithiobis (2-nitrobenzoic acid) (DTNB) and $0.4 \mathrm{ml}$ of doubledistilled water were added and the mixture was shaken. The absorbance was read at $412 \mathrm{~nm}$ within $15 \mathrm{~min}$ (Santhosh kumar et al., 2010).

\subsubsection{Estimation of catalase}

Blank 1: buffer $1 \mathrm{ml}$ - this only for blanking the instrument.

Blank 2: $1 \mathrm{ml} \mathrm{H}_{2} \mathrm{O}_{2}+100 \mu \mathrm{l}$ buffer $+1 \mathrm{ml}$ ammonium molybdate. - Read at $405 \mathrm{~nm}$

Blank 3: $1.1 \mathrm{ml}$ buffer $+1 \mathrm{ml}$ ammonium molybdate read at $405 \mathrm{~nm}$

Add $1 \mathrm{ml}$ of $\mathrm{H}_{2} \mathrm{O}_{2}$ to $100 \mu \mathrm{l}$ of Sample and mix well, after 60 seconds add $1 \mathrm{ml}$ ammonium molybdate and read the absorbance at $405 \mathrm{~nm}$ (Goth., 1991). One unit of the enzyme was defined as millimoles of $\mathrm{H}_{2} \mathrm{O}_{2}$ degraded/min/milligram of protein.

\subsubsection{Estimation of superoxide dismutase}

For monitoring pyrogallol auto-oxidation, 20 to $80 \mu \mathrm{l}$ of pyrogallol was pipetted out and the volume was made up to $100 \mu \mathrm{l}$ with $0.01 \mathrm{~N} \mathrm{HCl}$. To this $600 \mu \mathrm{l}$ of Tris $-\mathrm{HCl}$ buffer, $100 \mu 1$ of DETPA, $100 \mu$ of Tris EDTA and $100 \mu 1$ of distilled water was added. For the sample assay,
$50 \mu 1$ of pyrogallol and $50 \mu 1$ of the sample were added and the reaction was initiated \& measured at $420 \mathrm{~nm}$ at a constant temperature of $25^{\circ} \mathrm{c}$ for $3 \mathrm{~min}$ at $0.5 \mathrm{~nm}$ bandwidth. One unit SOD activity is the amount of enzyme that inhibits the rate of auto-oxidation of pyrogallol by 50 percent (Maneesha Ram et al., 2016).

2.5.5 Estimation of Brain Thiobarbituric acid reactive species (TBARS)

The whole brain TBARS level was measured by the method of (Ohokawa et al., 1979) with slight modifications. To $0.2 \mathrm{ml}$ brain homogenate, $0.2 \mathrm{ml}$ sodium dodecyl sulphate (SDS), $1.5 \mathrm{ml}$ of $30 \%$ acetic acid (pH-3.5), were added and made up the volume up to $4.0 \mathrm{ml}$ with distilled water (DW) and incubated at $95{ }^{\circ} \mathrm{C}$ for $60 \mathrm{~min} .1 .0 \mathrm{ml}$ of DW and $5.0 \mathrm{ml}$ of $30 \%$ acetic acid ( $\mathrm{pH}-3.5)$, was added and centrifuged at the $4000 \times \mathrm{g}$ for $10 \mathrm{~min}$. The absorbance of developed colour in organic layer was measured spectrophotometrically at $532 \mathrm{~nm}$. The absorbance from a standard curve generated using $1,1,3,3$, tetra-methoxy propane as standard was extrapolated (Sharma et al., 2008, Ohokawa et., 1979).

\subsection{Statistical analysis:}

All data are presented as Mean \pm S.E.M. The significance of difference among the groups were assessed using one way analysis of variance(ANOVA) followed by Tukey's test using Graph pad PRISM software and $\mathrm{p} \leq 0.05$ was considered significant.

\section{Results}

3.1. Effect of pterostilbene on locomotor activity using actophotometer :

Schizoprenia was assessed by locomotor activity in Actophotometer and the effect of pterostilbene on locomotor activity were shown in Fig: 1. Administration of ketamine showed significant $(\mathrm{P}<0.001)$ increase in locomotor activity in Group II when compared with Group I, Group III and IV showed significant (P < $0.001)$ decrease in locomotor activity when compared with Group II.

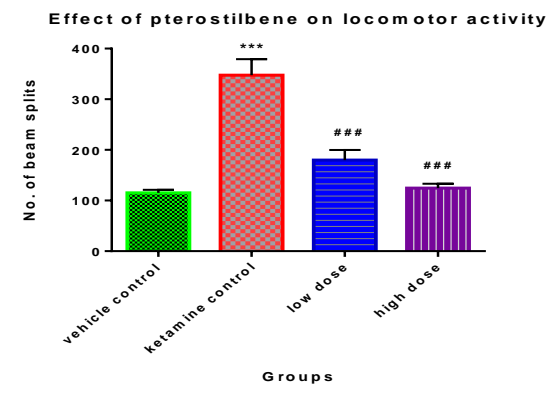

Fig. 1: Effect of pterostilbene on locomotor activity

Values are expressed as mean \pm SEM of $n=6$ animals. Superscript letters represents the statistical significance done by ANOVA, followed by Tukey's tests. 
${ }^{* * *} \mathrm{P}<0.001$ Compared with vehicle control; ${ }^{\# \#} \mathrm{P}<0.001$ Compared with Negative Control.

\subsection{Effect of pterostilbene on Y-Maze activity}

Fig: 2 shows the results for the performance of mice in Y-Maze task in which spatial recognition memory performance as alternation behaviour can be examined. The percentage alterations of Group II significantly ( $\mathrm{P}<$ 0.001 ) lowered when compared with Group I, there was a significant $(\mathrm{P}<0.01$,$) and (\mathrm{P}<0.001)$ increase in percentage alterations in Group III and Group IV when compared with Group II.

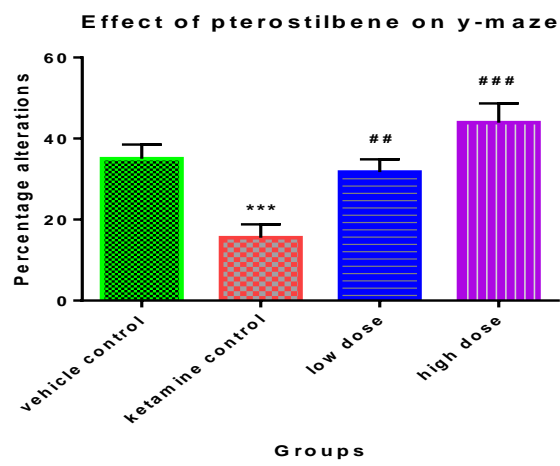

Fig. 2: Effect of pterostilbene on y-maze

Values are expressed as mean \pm SEM of $n=6$ animals. Superscript letters represents the statistical significance done by ANOVA, followed by Tukey's tests. ${ }^{* * * *} \mathrm{P}<0.001$ Compared with vehicle control; ${ }^{\# \# *} \mathrm{P}<0.001$, ${ }^{\# \#} \mathrm{P}<0.01$ Compared with Negative Control.

\subsection{Open field habituation test}

Effect of pterostilbene on open field exploration were shown in Fig: 3 and Fig: 4. The exploratory behaviour (i.e.) the number of line crossings and nose poking increased significantly $(\mathrm{P}<0.001)$ in Group II on comparison with Group I. Group III and Group IV showed significance $(\mathrm{P}<0.001)$ and $(\mathrm{P}<0.001)$ decrease in line crossings and nose poking when compared with Group II.

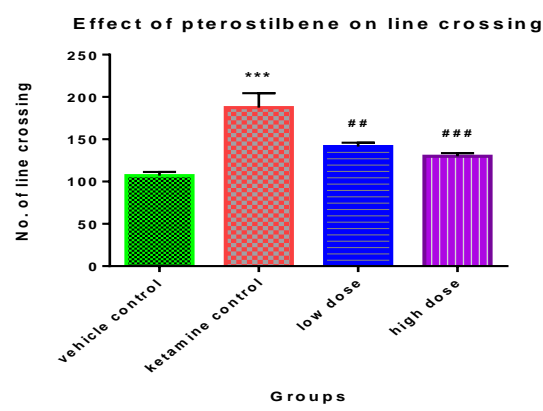

Fig. 3: Effect of pterostilbene on line crossing

Values are expressed as mean \pm SEM of $n=6$ animals. Superscript letters represents the statistical significance done by ANOVA, followed by Tukey's tests.
${ }^{* * *} \mathrm{P}<0.001$ Compared with vehicle control; ${ }^{\# \#} \mathrm{P}<0.001$, Compared with Negative Control.

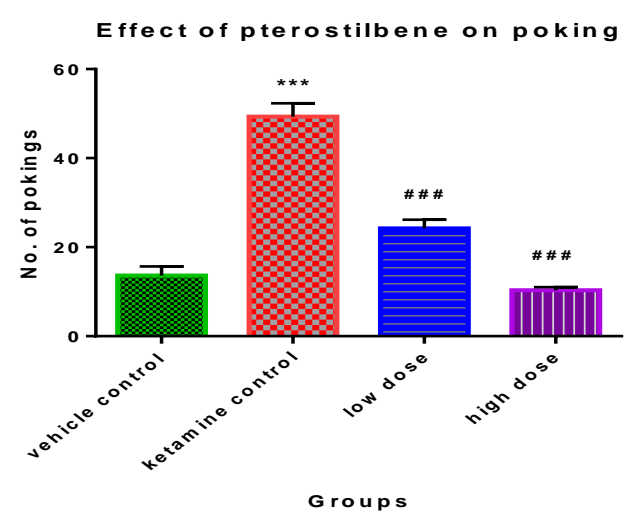

Fig. 4: Effect of pterostilbene on poking

Values are expressed as mean \pm SEM of $n=6$ animals. Superscript letters represents the statistical significance done by ANOVA, followed by Tukey's tests. ${ }^{* * * *} \mathrm{P}<0.001$ Compared with vehicle control; ${ }^{\# \# \#} \mathrm{P}<0.001$, Compared with Negative Control.

\subsection{Forced swim test activity}

Fig:5 shows the effect of pterostilbene on the duration of immobility in forced swim test. The duration of immobility was increased significantly $(\mathrm{P}<0.001)$ in Group II on comparison with Group I, Group III and Group IV showed significant $(\mathrm{P}<0.01)$ and $(\mathrm{P}<0.001)$ decrease in the duration of immobility when compared with Group II. There observed statistical significance (P $<0.01$ ) among Group I and Group III, Group III and Group IV (P < 0.001).

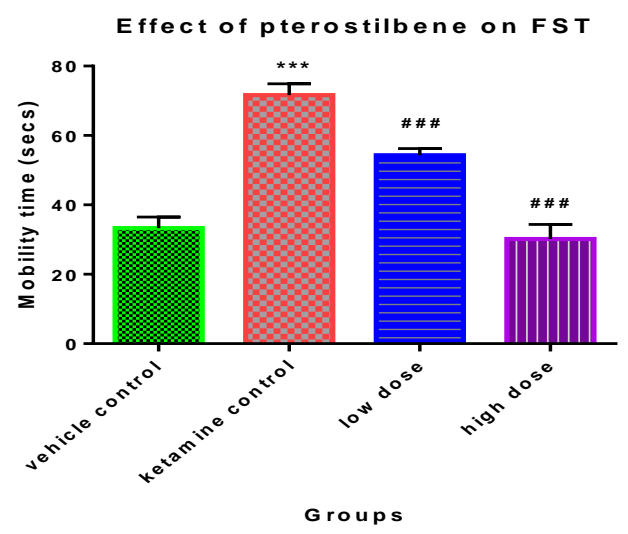

Fig. 5: Effect of pterostilbene on FST

Values are expressed as mean \pm SEM of $n=6$ animals. Superscript letters represents the statistical significance done by ANOVA, followed by Tukey's tests. ${ }^{* * * *} \mathrm{P}<0.001$ Compared with vehicle control; ${ }^{\# \# \#} \mathrm{P}<0.001$, Compared with Negative Control.

\subsection{Reduced Glutathione (GSH)}

The results were shown in Table 1. The GSH levels were significantly $(\mathrm{P}<0.001)$ decreased in Group II when 
compared with Group I. There was observed significant $(\mathrm{P}<0.05)$ and $(\mathrm{P}<0.001)$ increase in enzyme levels in Group III and Group IV on comparison with Group II.

\subsection{Catalase enzyme activity}

The catalase levels were shown in Table 1 . The enzyme levels were significantly $(\mathrm{P}<0.05)$ decreased in Group II when compared with Group I, there was a significant (P $<0.05)$ and $(\mathrm{P}<0.05)$ increase in catalase activity in Group III and Group IV when were compared with Group II.

\subsection{Superoxide dismutase (SOD)}

The effect of pterostilbene on anti-oxidant enzyme SOD was shown in Table 1. The enzyme levels were significantly $(\mathrm{P}<0.001)$ decreased in Group II when compared with Group I, there was a significant ( $\mathrm{P}<$ $0.001, \mathrm{P}<0.001)$ increase in enzyme levels in Group III and Group IV when compared with Group II ( $<<0.001)$.

\subsection{Thiobarbituric acid reactive species (TBARS)}

Effect of pterostilbene on lipid peroxidation markers were shown in Table 1 . The brain TBARS significantly $(\mathrm{P}<0.05)$ increased in Group II when compared with Group I. Group III and Group IV significantly $(\mathrm{P}<0.05)$ and $(\mathrm{P}<0.05)$ decreased TBARS when compared with Group II.

\subsection{Acetyl cholinesterase enzyme activity}

Effect of pterostilbene on AchE was depicted in Table 1. Administration of ketamine significantly ( $\mathrm{P}<0.001$ ) increased the AchE activity when compared with Group I, Group III and Group IV significantly ( $<<0.001)$ and $(\mathrm{P}<0.001)$ attenuated the raise in enzyme level when compared with Group II.

Table1: Effect of pterostilbene on Biochemical estimations

\begin{tabular}{|l|l|l|l|l|l|}
\hline Groups & $\begin{array}{l}\text { GSH } \\
\text { (U/mg protei }\end{array}$ & $\begin{array}{l}\text { Catalase } \\
(\mathbf{U} / \text { mgprotein) }\end{array}$ & $\begin{array}{l}\text { SOD } \\
(\mathbf{U} / \mathbf{m i n} / \mathbf{m g p r o t e i n})\end{array}$ & $\begin{array}{l}\text { TBARS } \\
(\mathbf{n m o l} / \mathbf{m g} \\
\text { protein })\end{array}$ & $\begin{array}{l}\text { AchE } \\
(\mu \mathbf{m o l} / \mathbf{m i n} / \mathbf{m g}\end{array}$ \\
\hline Group I(Vehicle) & $0.19 \pm 0.02$ & $0.16 \pm 0.02$ & $22.82 \pm 2.06$ & $3.41 \pm 0.31$ & $1.64 \pm 0.27$ \\
\hline Group II (KET 50 mg/kg) & $0.02 \pm 0.00^{* * *}$ & $0.07 \pm 0.00^{*}$ & $1.59 \pm 0.19^{* * *}$ & $5.22 \pm 0.55^{*}$ & $6.82 \pm 0.17^{* * *}$ \\
\hline GroupIII(PTR10mg/kg+KET) & $0.11 \pm 0.01^{\#}$ & $0.15 \pm 0.01^{\#}$ & $12.87 \pm 0.94^{\# \# \#}$ & $5.12 \pm 0.42^{\#}$ & $3.69 \pm 0.19^{\# \# \#}$ \\
\hline GroupIV(PTR20mg/kg+KET) & $0.17 \pm 0.02^{\$ \$}$ & $0.16 \pm 0.02^{\$}$ & $20.35 \pm 2.02^{\$ \$ \$}$ & $3.25 \pm 0.36^{\$}$ & $2.25 \pm 0.26^{\$ \$}$ \\
\hline
\end{tabular}

Values are expressed as mean \pm SEM of 6 animals. Superscript symbols represent the statistical significance done by ANOVA, followed by Tukey's multiple comparison tests. ${ }^{* * *} \mathrm{p}<0.001,{ }^{* *} \mathrm{p}<0.01,{ }^{*} \mathrm{p}<0.05$ indicates comparison of negative control group with control group. ${ }^{\# \#} \mathrm{p}<0.001,{ }^{\#} \mathrm{p}<0.01,{ }^{\#} \mathrm{p}<0.05$ indicates comparison with ketamine control.

\section{Discussion}

Schizophrenia is a chronic debilitating psychiatric disorder affecting as many as $1 \%$ of the population worldwide (Silveri Kalpana et al., 2013). The clinical features of the heterogeneous disorder schizophrenia usually appear in late adolescence or early adulthood, and can be divided into positive, negative and cognitive symptoms. Delusions (paranoia, false beliefs), hallucinations (visual and auditory), and thought disturbances are classified as positive symptoms, whereas negative features include depression, withdrawal from social contacts, incapability to feel pleasure (anhedonia) and flattening of emotional responses. Cognitive defects involve deficits in attention and memory (Rajiv Tendon et al 2009).
The residual symptoms especially negative and cognitive symptoms are closely correlated with the degree of disability than the positive symptoms (Buckley et al., 2007). Atypical antipsychotic medication provides hope in the management of negative symptoms, but the success remains limited. (Silveri Kalpana et al. 2013). The dopaminergic hypothesis came about from the observation that drugs that antagonized dopamine were found to be effective in the treatment of schizophrenia. Dopamine system has been proposed to account for the positive and negative symptoms of schizophrenia that emerge during adolescence. Dopamine antagonists are effective only in treating positive symptoms associated in schizophrenia (Howes et al., 2009).

The goal of the study was to assess the efficacy of pterostilbene using ketamine-induced schizoprenia 
model in mice with respect to some selected behavioural phenotypes that correlate with certain sections of symptoms observed in schizophrenia. In the present study the behavioural models such as locomotor activity, forced swimming test, Y-maze tests were conducted and Acetylcholinesterase enzyme, TBARS, SOD, CAT and GSH levels in brain tissue were estimated.

Locomotor activity is a measure of the positive symptoms in schizophrenia. Positive symptoms include aggressive and stereotype behaviour. Results in the present study indicate that chronic treatment of ketamine (50 mg/kg, i.p.) produced hyper locomotor response. It has been reported that dopaminergic pathways are critical for the control of locomotor activities. Ketamine increased the dopamine levels (Chatterjee et al 2011). The locomotor activity was almost normal when high and low dose of pterostilbene was given in ketamine induced mice and it is an indication of protection from the occurrence of positive symptoms in schizophrenia.

Forced swim-induced immobility in rodents is an acceptable animal model of schizophrenia that reflects a state of despair in the rat and the reduction in the immobility time serves as the index of antidepressant activity (Silveri Kalpana et al. 2013; Yue Hou et al.,2013; Daine B.Fraga et al.,2013). In our study chronic administration of ketamine for 14 days induced enhancement of the mobility duration of mice in forced swimming test. The reduction in mobility duration was significant when low dose and high dose of pterostilbene was given in ketamine received mice and it is an indication of protection from the occurrence of negative symptoms in schizophrenia.

Cognitive impairments such as deficits in attention, executive function, short-term memory, and long-term memory, are core symptoms in patients with schizophrenia. Among these, learning and memory impairments are known to be particularly severe, and they are suggested to be major determinants of the amount of disability in patients with schizophrenia (Yue Hou et al.,2013; Harvey et al.,2004; ,Saykin et al.,1991).

The active Y-maze task has been used to evaluate the effects of antipsychotic drugs on learning and memory function. Pterostilbene improved the ketamine induced cognitive symptoms in schizophrenic mice in our study.

Acetylcholine plays a critical synaptic role in the initial stages of memory formation. Ketamine blocks nicotinic cholinergic receptors and there by suppresses glutamate release. Blockade of these receptors, induces increased ACh release activating cholinesterase enzyme which, in turn, interferes with hippocampal memory formation (Silveri Kalpana et al. 2013) .Pterostilbene reduced the Ache levels and produced potentiating effect.

Oxidative stress refers to an imbalance between the formation of cellular oxidants and the antioxidative processes and it occurs when the production of reactive oxygen radicals (or free radicals) increases beyond the physiological antioxidant protective mechanisms. It plays an important role in neuronal injury and schizophrenic pathophysiology (Bošković et al., 2011; Wu et al., 2013). Oxidative stress activates GSK3 $\beta$ in rodents (Jean-Martin Beaulieu., 2012). Different subanesthetic doses of ketamine increase oxidative stress in the brain of rodents (Oliveira et al.,2009). Recent studies have implicated GSK-3 $\beta$ signaling in schizophrenia (Kozlovsky et al., 2000; Emamian et al., 2004; Lovestone et al., 2007; Freyberg et al., 2010). Moreover, GSK-3 $\beta$ is a target for several antipsychotics that decrease the activity of GSK-3 $\beta$ by causing the phosphorylation of GSK-3 $\beta$ at Ser9 (Mahajan et al.,2013; Kozlovsky et al., 2006). In fact, the NMDA receptor antagonists PCP and MK-801 have been found to increase GSK-3 $\beta$ activity both in vitro (Elyaman et al.,2002) and in vivo. We measured the amount of SOD, TBARS, GSH, CAT and AchE in brain of mice treated with repeated ketamine. Both high and low doses of pterostilbene reduced the oxidative stress.

\section{Conclusion}

Schizophrenia is a chronic and disabling mental illness affecting millions of people worldwide. The symptoms of schizophrenia are classified into positive, negative and cognitive symptoms. New receptor targets and drugs have being evaluated for addressing the multifaceted syndrome of schizophrenia. The results suggest that the drug pterostilbene could be a new third-generation therapeutic agent for treating schizophrenia.

\section{References}

1. Avinash P, Arun Reddy R, Nazia Begum, et al (2016). Neuroprotective Effect of Garcinia Mangostana on Streptozotocin Induced Sporadic Type Alzheimer's Disease in Mice. Int J App Pharm Sci and Res. 1(1):815.

2. B Paul, I Masih, J Deopujari, et al (1999). “Occurrence of resveratrol and pterostilbene in age-old darakchasava, an ayurvedic medicine from India," Journal of Ethnopharmacology. vol. 68, no. 1-3, pp. 71-76.

3. Bošković M, Vovk T, Kores Plesničar B et al (2011). Oxidative stress in schizophrenia.Neuropharmacol. 9:301-12.

4. Buckley PF, Stahl SM (2007). Pharmacological treatment of negative symptoms of schizophrenia: therapeutic opportunity or cul-de-sac? Acta Psychiatr Scand. 115:93-100.

5. Chang J, Rimando A, Pallas M, et al (2012). Low-dose pterostilbene, but not resveratrol, is a potent neuromodulator in aging and Alzheimer's disease. Neurobiol Aging. 33(9):2062-71. 
6. Chatterjee M, Ganguly S, Srivastava M, et al (2011) Effect of 'chronic' versus 'acute' ketamine administration and its 'withdrawal' effect on behavioural alterations in mice: implications for experimental psychosis. Behav Brain Res. 216(1):247-54.

7. CH Maneesha Ram, Nazia Begum, Naveen Pathakala, et al (2016). Neuroprotective Effect of Nevirapine On Cerebral Ischemia Stroke by Middle Cerebral Artery Occlusion in Wistar Rats. Int J App Pharm Sci Res. $1(1): 16-24$

8. Daiane B. Fraga, Gislaine Z. Reus, Helena M, et al (2013). Ketamine alters behavior and de3creases BDNF levels in the rat brain as a function of time after drug administration. Revista Brasileira de Psiquiatria. 35:262-266.

9. Dennis K. Miller, Clark E. Oelrichs, Andrew S. Sage, et al (2013). Repeated resveratrol treatment attenuates methamphetamine-induced hyperactivity and [3H]dopamine overflow in rodents.Neurosci Lett. 554:53-8.

10. Elder GA, Ragnauth A, Dorr N, et al (2008). Increased locomotor activity in mice lacking the low-density lipoprotein receptor. Behav. Brain Res. 191:256-265.

11. Elyaman W, Terro F, Wong NS, et al (2002). In vivo activation and nuclear translocation of phosphorylated glycogen synthase kinase-3beta in neuronal apoptosis: links to tau phosphorylation. Eur. J. Neurosci. 15 (4):651-660.

12. Emamian ES, Hall D, Birnbaum MJ, et al (2004). Convergent evidence for impaired AKT1-GSK3beta signaling in schizophrenia. Nat. Genet. 36(2), 131-137.

13. Fendt M, Lex A, Falkai P, et al (2008). Behavioural alterations in rats following neonatal hypoxia and effects of clozapine: implications for schizophrenia. Pharmacopsychiatry. 41:138-145.

14. Freyberg Z, Ferrando SJ, Javitch JA (2010). Roles of the Akt/GSK-3 and Wnt signaling pathways in schizophrenia and antipsychotic drug action. Am. J. Psychiatry 167 (4), 388-396.

15. Goth L (1991). 'A simple method for determination of serum catalase activity and revision of reference range'. Clinica Chimica Acta. 196:143-151.

16. Harshalkumar Mahajan and Shrikant Pawar (2013). In vivo antimanic activity of lithium and carbamazepine in ketamine induced mania in wistar albino rats. Int $J$. LifeSc. Bt \& Pharm. Res. 2013;2(4):118-126

17. Harvey PD, Green MF, Keefe RS, et al (2004) Cognitive functioning in schizophrenia: a consensus statement on its role in the definition and evaluation of effective treatments for the illness. J Clin Psychiatry. 65:361-372.

18. Howes, OD, Kapur S, (2009). The Dopamine Hypothesis of Schizophrenia: Version III-The Final Common Pathway. Schizophrenia Bulletin. 35(3):549562. http://doi.org/10.1093/schbul/sbp006

19. Jean-Martin Beaulieu (2012). A role for Akt and glycogen synthase kinase-3 as integrators of dopamine and serotonin neurotransmission in mental health. $J$ Psychiatry Neurosci. 37(1):7-16.

20. JK Grover, V Vats, and SS Yadav (2005). Pterocarpus marsupium extract (Vijayasar) prevented the alteration in metabolic patterns induced in the normal rat by feeding an adequate diet containing fructose as sole carbohydrate. Diabetes, Obesity and Metabolism. 7(4):414-420.

21. Joseph JA, Fisher DR, Cheng V, et al (2008). Cellular and behavioral effects of stilbene resveratrol analogues: implications for reducing the deleterious effects of aging. J Agric Food Chem. 56(22):10544-51.

22. Kozlovsky N, Amar S, Belmaker RH, et al (2006). Psychotropic drugs affect Ser9- phosphorylated GSK-3 beta protein levels in rodent frontal cortex. Int. J. Neuropsychopharmacol. 9 (3):337-342.

23. K Sharath Kumar, Nazia Begum, Rahul M Kakalij, et al (2016). Neuroprotective Activity of Ethanolic Extract of Polyherbal Formulation on Streptozotocin Induced Alzheimer's in Mice. Int J App Pharm Sci Res. 1(1):1-7.

24. Lovestone S, Killick R, Di Forti, et al (2007). Schizophrenia as a GSK-3 dysregulation disorder. Trends Neurosci. 30(4):142-149.

25. Manickam M, Ramanathan M, Jahromi MA, et al (1997). Antihyperglycemic activity of phenolics from Pterocarpus marsupiurn. J Nat Prod. 60:609-610.

26. Maria RR, Ivan I, Maria CBR, et al (2005). Effect of lyophilized Vaccinium berries on memory, anxiety and locomotion in adult rats. Pharmacol. Res. 52:457-462.

27. Mikstacka R, Przybylska D, Rimando AM, et al (2007). Inhibition of human recombinant cytochromes P450 CYP1A1 and CYP1B1 by trans-resveratrol methyl ethers. Mol Nutr Food Res. 51:517-524.

28. Ming-Huan Chan, Pao-Hsiang Chiu, Chia-Yu Lin, et al (2012). Inhibition of glycogen synthase-3 attenuates psychomimetic effects of ketamine. Schizophrenia Research. 136:96-103

29. Nandini R. Pai and Deepnandan S. Dubhashi (2010). Studies of Antipsychotic drugs as potential schizophrenia agents, J. Chem. Pharm. Res. 2(1): 458-472. 
30. Noda Y, Mamiya T, Furukawa H, et al (1997). Effects of antidepressants on phencyclidine-induced enhancement of immobility in a forced swimming test in mice. Eur $J$ Pharmacol. 324:135-40.

31. Noda Y, Kamei H, Mamiya T, et al (2000). Repeated phencyclidine treatment induces negative symptom-like behavior in forced swimming test in mice: imbalance of prefrontal serotonergic and dopaminergic functions. Neuropsychopharmacology. 23:375-87.

32. Ohokawa H, Ohishi N, Yagi K (1979). Assay for lipid peroxides in animal tissues by thiobarbituric acid reaction. Anal Biochemistry.95:351-8.

33. P Langcake, CA Cornford, RJ Pryce (1979), Identification of pterostilbene as a phytoalexin from Vitis vinifera leaves. Phytochemistry. 18(6):1025-1027.

34. Rajiv Tandon, Matcheri S. Keshavan, Henry A. Nasrallah (2008). Schizophrenia facts. Schizophrenia, "Just the Facts" What we know in 2008.2. Epidemiology and etiology. Schizophrenia Research. 102:1-18.

35. Rimando AM, Cuendet $\mathrm{M}$, Desmarchelier $\mathrm{C}$, et al (2002). Cancer chemopreventive and antioxidant activities of pterostilbene, a naturally occurring analogue of resveratrol. J Agric Food Chem. 50:3453-3457.

36. Rimando AM, Nagmani R, Feller DR, et al (2005). Pterostilbene, a new agonist for the peroxisome proliferator-activated receptor alpha-isoform, lowers plasma lipoproteins and cholesterol in hypercholesterolemic hamsters. J Agric Food Chem. 53:3403-3407.

37. Remsberg CM, Yáñez JA, Ohgami Y, et al (2008). Pharmacometrics of pterostilbene: preclinical pharmacokinetics and metabolism, anticancer, antiinflammatory, antioxidant and analgesic activity. Phytother Res. 22(2):169-79.

38. Santosh kumar Tota., Himani Awasthi., Pradeep Kumar Kamat, et al (2010). Protective effect of quercetin against intracerebral streptozotocin induced reduction in cerebral blood flow and impairment of memory in mice. Behavioural Brain Research. 209:73-79.

39. Satheesh MA, Pari L (2008). Effect of pterostilbene on lipids and lipid profiles in streptozotocin-nicotinamide induced type 2 diabetes mellitus. J Appli Biomed. 6:3137.

40. Saykin AJ, Gur RC, Gur RE, et al (1991). Neuropsychological function in schizophrenia. Selective impairment in memory and learning. Arch Gen Psychiatry. 48:618-624.

41. Silveri Kalpana, Akondi Butchi Raju, Ms. Swathi Merugu (2014). Genestein, a phytoestrogens for the treatment of schizophrenia. IJSER. 4(7): 296-321.

42. Uma Devi Pongiya, Badarunnisa Mohammed Kandanath, Yalaga Rama Rao, et al., (2014). Protective effect of Hypericum hookerianum in reversing haloperidol induced schizophrenia-like behaviors in Swiss albino mice. Asian Journal of Biomedical and Pharmaceutical Sciences. 04 (32):14-23.

43. Wu JQ, Kosten TR, Zhang XY (2013). Free radicals, antioxidant defense systems, and schizophrenia. Prog Neuropsychopharmacol Biol Psychiatry. S02785846(13)00049-3

44. Yue Hou, Hongli Zhang, Guanbo Xie, et al (2013). Neuronal injury, but not microglia activation, is associated with ketamine-induced experimental schizophrenic model in mice. Progress in NeuroPsychopharmacology and Biological Psychiatry. 45:107116.

45. Yasuko Kitagishi, Mayumi Kobayashi, Kanae Kikuta, et al (2012). Roles of PI3K/AKT/GSK3/mTOR Pathway in Cell Signaling of Mental Illnesses. Hindawi Publishing Corporation, Depression Research and Treatment. 752563.

How to cite this article:

Devender Palsa, Nazia Begum, Jeevan Kommidi, Kapishwar Singh, Mahipal Yellu, Dr Vasudha Bakshi (2016). Neuroprotective effect of pterostilbene on ketamine induced schizophrenia in mice. Int J Appl Pharm Sci Res. 1(3):96-103. 